\title{
Caring for Dying Children and Their Families: MFTs Working at the Gates of the Elysian Fields
}

\author{
Ileana Ungureanu · Jonathan G. Sandberg
}

Published online: 23 February 2008

(C) Springer Science+Business Media, LLC 2008

\begin{abstract}
The constant comparison method was used to analyze seven in-depth interviews with Marriage and Family Therapists and some of their colleagues working with dying children and their families. The findings of the study revealed that working in these settings can encourage shifts in priorities, relationships, and beliefs about life and death, and can elicit professional growth. Also, it can carry with it significant costs such as emotional exhaustion, and hypervigilance about death. Implications for practice and training are discussed.
\end{abstract}

Keywords Marriage and family therapists · Dying children · Impact on personal and professional life

Stop the passing away. I know that where is no death, there is no love, - and still, I beg you Lord, stop the clock You measure our fading away with.

(Blaga 1982, p. 71)

Reflecting on his experience with suffering in the Nazi concentration camp, Viktor Frankl said: "what is to give light might endure burning" (Frankl 1984, p. 84). To me (first author), the experiences of suffering can indeed transform us, enlighten us and in the light of our experience can enlighten others. However, the same experience with suffering can cause lethal burns for another's soul. What kind of suffering might accompany the loss of a child? I (first author) have never had a child, I have never lost one. But my mother did, and her mother did as well. Perhaps, my maternal grandmother loved me so much not only because

In the Greek mythology, the Elysian Fields is the place where the souls of the heroes and the virtuous dwell in the afterlife. It is the equivalent of the Christian Heaven.

Portions of this paper were presented at the 65th Annual Conference of the American Association for Marriage and Family Therapy, Long Beach, CA, 2007.

I. Ungureanu $(\bowtie) \cdot$ J. G. Sandberg

Marriage and Family Therapy Program, Syracuse University, 426 Ostrom ave, Syracuse,

NY 13244, USA

e-mail: iungurea@syr.edu 
of who I am, but also because she lost her twins a few hours after she gave birth to them and she desperately wanted another child, my mother being her only surviving child. My paternal grandmother also lost a small child. In addition, my great-grandmother's son died at age three in an accidental death. Somehow the unexpressed pain of these family members found shelter in my soul. Perhaps in an attempt to have a better understanding of this type of suffering, I became curious about the impact of losing children on helping professionals.

When I (second author) was only two and a half years old my parents lost their infant daughter, my sister, to a respiratory illness. Though I have no clear cognitive memories of that time, the emotional imprint of Rochelle's passing has been with our family ever since. As recently as last Memorial Day, members of our family gathered at her gravesite. Subsequently, an in-person and electronic dialogue ensued about her death. In that discussion my dad said, "it still does not seem right that parents bury a child, children should be allowed to bury their parents." On another occasion he said:

The pain of her death never goes away, the intensity of the emotion remains the same (now over 35 years later), you just don't feel it as often, but when the flood of emotions comes back, it is just as strong.

I believe this and other formative experiences in my childhood are why I am drawn to write, teach, and counsel with others about the bittersweet experience of loss.

In a letter to a friend who had just lost his little girl Freud wrote:

The loss of a child is a trial from which the adult never recovers because he finds that part of himself which he projected in his descendent is amputated. The death of a child seems against the nature; when mourning the loss of an offspring the parent realizes that the natural order of the generations has been reversed. This mourning involves a pain that escapes both words and thoughts. Even the language does not have a name for those who lost a child. It has terms for those who lost the adults they loved (orphan, widow, widower), but there is no word to name the parents that have lost their child or the child that has lost a sibling. (Freud as cited in Ricoeur and Gentet 1996, p. 260)

The loss of a child is a loss unspeakable, it is not natural, it is outrageous, it is unjust, and it is not supposed to happen. And still it does happen. A child's death takes its toll not only on his or her parents, extended family or friends, but also on health professionals who work in a setting where they are constantly witnessing children's suffering and dying.

\section{Helping Professionals: The Toll of Caring}

Recently, there has been increased recognition of the effects of working with clients' traumatic issues on health professionals from different fields: mental health, nursing, and physicians. Authors conceptualize the impact of professional stress on mental health professionals as either burnout, secondary traumatization, or vicarious traumatization (Canfield 2005; Dunkley and Whelan 2006; Figley 1995; Hesse 2002; McCann and Pearlman 1990; McLean et al. 2003; Pearlman and Saakvitne 1995; Pensson et al. 2000; Witt Sherman 2004). The same concepts can be found in the literature as they relate to professional stress on therapists working with chronically ill or dying people (Becvar 2003; Catalan et al. 1996, Davies et al. 1996; Henning 2005; Kaplan 2000; Lattonzi-Licht in Papadatou 1991; Lyckholm 2001; Papadatou 2000; Papadatou et al. 2002; Pensson et al. 2000; Rushton 2004; Witt Sherman 2004). 
Professional burnout is the term used most often for describing this type of impact on mental health professionals, nurses or physicians who are working with dying clients/ patients (Catalan et al. 1996; Friedman 1985; Lyckholm 2001; McLean et al. 2003; Pensson et al. 2000; Witt Sherman 2004). Most of these studies list two groups of manifestations of burnout: physical and emotional. In the physical category researchers identify changes in appetite, headaches, exhaustion, and sleep disturbances. Among the emotional manifestations listed are hopelessness, cynicism, anger outbursts, low self-esteem, isolation, memory disturbances, and impaired judgment leading to clinical error. In her review of the literature on professional stress, Canfield (2005) noticed that some authors tend to blame the work environment in which professionals work. She mentions "six specific work environment sources of burnout: work overload; lack of control; insufficient rewards; unfairness; breakdown of community; and value conflict" (p. 84).

Other authors prefer to conceptualize the impact on health professionals as compassion fatigue or secondary traumatic stress (Figley 1995; Hesse 2002). Figley suggests that mental health care providers who are working with clients dealing with posttraumatic stress disorder (PTSD) tend to identify with their clients suffering through their empathic abilities and thus experience trauma themselves.

Working with children who live with life-threatening diseases exposes professionals to the PTSD symptoms of their clients. In a recent article, Kazak et al. (2004) presented the findings of a quantitative research study on the presence of PTSD symptoms in adolescent survivors of childhood cancer and their parents. Their findings suggest that PTSD symptoms were found in both the adolescent cancer survivors and in their parents, parents reporting more symptomatology than the former patients.

A prolonged exposure to clients dealing with PTSD symptoms can contribute to dysfunction, which Figley (1995) called compassion fatigue or secondary traumatic stress. The symptoms associated with this entity are similar to those of PTSD (American Psychiatric Association 2000) and include intrusive thoughts, physiologic arousal, hypervigilance, and isolation, among others.

Vicarious traumatization is another conceptualization of the same phenomenon (McCann and Pearlman 1990). In a recent article on the effects of trauma work on professionals, Dunkley and Whelan (2006) proposed vicarious traumatization as the "most appropriate concept given that it relates specifically to trauma work, [and] incorporates intrinsic and extrinsic factors" (p. 107). They also stated that vicarious traumatization is a natural by-product of doing trauma work and "is a crucial issue for helping professionals" (p. 107). McCann and Pearlman (1990) argued that from a constructivist self-development stand-point trauma can disrupt the professional's "cognitive schemata" in one or more of the five fundamental needs: safety, trust, self-esteem, control, and intimacy. Pearlman and Saakvitne (1995) summarize the alterations associated with this phenomenon:

"These alterations include shifts in the therapist's identity and world view; in the ability to manage strong feelings, to maintain a positive sense of self and connect to others; and in spirituality or sense of meaning, expectations, awareness, and connection; as well as in basic needs for and schemata about safety, esteem, trust, and dependency, control, and intimacy.” (p. 152)

Another recent article is addressed specifically to burnout among marriage and family therapists (MFTs; Rosenberg and Pace 2006), suggesting that these professionals are susceptible to low-to-moderate levels of burnout. However, this study does not address how specific issues, or different types of human suffering, have an impact on mental health professionals in general and paticularly on MFTs. 


\section{MFTs Working with Death and Dying Issues}

Becvar (2003) specifically addressed the impact on MFTs who work with loss, particularly with death and dying issues. Becvar noted the lack of research in the MFT literature with this particular focus. Consistent with the literature reviewed above, she conceptualized the suffering of MFTs as compassion fatigue or vicarious traumatization. The author mentions that "when grief therapy is one's chosen area it is not at all unusual to be preoccupied with or hunted by the pain clients may be experiencing, thus placing great strain on the emotional and spiritual resources of the professional" (p. 471). In her article, the author presents the reader with some guidelines for preventing problems related to the focus on death and dying, highlighting the beneficial aspects of team support, peer supervision, as well as a holistic approach to self-care of the MFT.

The MFT literature is still characterized by a paucity of research regarding the impact of working with death and dying issues. Even though recent studies describe the intensity and duration of the impact of stress associated with cancer on both the patients and their parents (Kazak et al. 2004), there is almost no reference to the specific MFT population working with children with life-threatening diseases or with the death of children and their families. However, due to the nature of their work, it may be that MFTs have a double-exposure to trauma, having to address the child's and the parents' trauma. In an attempt to have a better understanding of the impact of working with dying children on professionals, the review of literature was expanded to include other helping professionals.

\section{Health Professionals Working with Dying Children}

The literature related to the impact of caring for dying children comes almost exclusively from the nursing field and particularly from pediatric oncology nursing or pediatric palliative care. In a chapter dedicated to the impact on pediatric palliative care professionals, Rushton (2004) refers to the impact of working with dying children as caregiver suffering mentioning that burnout, compassion fatigue, secondary traumatic stress, and vicarious traumatization are all related concepts. In addition to the common factors of the entities mentioned above, authors writing on aspects of caring for dying children tend to identify another specific aspect: professionals' experience of loss and grief (Davies et al. 1996; Kaplan 2000; Papadatou 2000; Papadatou et al. 2002; Rashotte et al. 1997; Rushton 2004).

Papadatou (2000) grouped the losses experienced by care providers into six major categories: loss of a close relationship with a patient, loss due to a professional's identification with the pain of a family member, loss of one's unmet goals and expectations and one's professional self-image and role, losses related to one's personal system of beliefs and assumptions about life, past unresolved losses or anticipated future losses of professionals, and confronting the death of self. The loss due to care provider identification with the pain of family members is not uncommon, especially when the professional has the same family role as a particular relative of the child. Another very common category of loss experienced by professionals working with death and dying is related to one's personal system of beliefs and assumptions about life, especially for those caregivers who believe in 'having control' in a just and safe world. "Disconfirmation of such an assumptive world may trigger intense feelings of meaninglessness, hopelessness, and other poignant grief reactions, especially over the death of children, adolescents, and young adults" (Papadatou 2000, p. 62) 
In their study, Papadatou et al. (2002) have shown that "the grieving experienced by health professionals occurs as a process of an ongoing fluctuation between experiencing grief reaction by focusing on the loss experience, and avoiding or repressing grief reactions by moving away from the loss experience" (p. 64). These two aspects of caregivers' grieving processes are essential for the professional's well-functioning, on both personal and professional levels. When health care professionals focus on the loss, they usually experience "sorrow, depression, and sometimes anger and guilt after the death of a patient. Some cry, and most think intensively of the patient and his or her family members" (p. 65). In the process of avoiding/repressing grief reactions, the caregivers might move away from the loss by denying it, by numbing, retreating to practical tasks imposed by their professional role, or even de-humanizing the dying child who becomes a body that needs care rather than a whole human being. Another common avoidance reaction noticed by this author relates to avoidance of contact with either the child and/or his/her family.

\section{MFTs Working with Dying Children}

More and more MFTs are specializing in medical family therapy and some of them choose to focus on death and dying issues, which requires "great commitment and much emotional involvement" (Becvar 2003, p. 471). When the focus is on working with dying children and their families, the struggle to balance emotional involvement with the clients, while providing good care, might be particularly burdening for MFTs and other professionals (Becvar 2003; Kaplan 2000; Papadatou 2000). In addition, through the systemic lens by means of which they conceptualize the world as well as suffering, MFTs might be at a greater risk since they are trained to look at the interplay of the suffering of the child, families, and members of the health care team.

The literature provides little information about how MFTs working with families with a dying child are impacted by the exposure to this type of human suffering. Because so little is known about this from the point of view of MFTs, the purpose of this study was to invite MFTs and other professionals working in a collaborative team to describe their own experiences. Therefore, a qualitative method was selected to highlight the voices of those who every morning face the possibility that during the workday they will meet death through a child they know and love. In addition, the approach allowed the authors to discover how meaning is made, particularly regarding suffering in a work setting.

\section{Method}

\section{Procedure}

Participants were recruited from the following sites: a Pediatric Hematology-Oncology unit from a Northeastern Medical University, and from a Hospice in the same region. Professionals were identified as participants based on the following three criteria:

1. Participants must work in a setting were children with life-threatening diseases are treated.

2. Participants must have worked in this particular setting for at least 1 year.

3. Participants must be either MFTs themselves or work closely with one. 
Letters of invitation to participate in the study were sent via e-mail to potential participants. Eight of the nine invitations e-mailed were returned. Seven were positive, one was negative and one of the potential participants did not respond at all. A phone call was made to each respondent who was willing to participate and an interview was scheduled. At the beginning of each interview session the investigator presented the participant with an informed consent form. The interviews were audio taped and conducted by the first author.

Each of the seven interviews followed a semi-structured schedule (see Appendix A), which served to focus the investigators' questions on the specific impact of the work setting on the health professionals. The interviews lasted between 60 and 90 min and were conducted in a therapy room of the Pediatric Hematology-Oncology unit. The interviews were conducted separately to maintain privacy. This study was reviewed and approved by the Institutional Review Board for the Protection of Human Subjects of a university in the northeast U.S.

\section{Participants}

Participants in the study were predominantly Caucasian (six Caucasian, one AfricanAmerican) and predominantly female (six female, one male). Four MFTs, one nurse, one social worker, and one pediatric chaplain participated in the study. The average age of the sample was 46, ranging from 26 to 61 . Six of the participants are parents themselves. Three of the participants had small children (under 12) and the other three were parents of adult children. One participant did not have children. The average time the participants worked in their particular setting at the moment of the interview was 6 years, with a range of $2-$ 16 years.

\section{Analysis}

For this study the method used to analyze data was the constant comparison method (Corbin and Strauss 1990; Dye et al. 2000). This is the principal method of investigation for a grounded theory approach to qualitative research: "Grounded theory is a methodology based on theory development from data that are collected and analyzed systemically and recursively" (Echevaria-Doan and Tubbs 2005, p. 42). This method of scientific inquiry aims to inductively develop new theory, unlike traditional methods that are focused on deductively testing and verifying extant theory. The constant comparison method refers to a "continual process of categorization, sorting and resorting, and coding, and recoding of data for emergent categories of meaning." (Echevaria-Doan and Tubbs 2005, p. 49). The constant comparative method helps researchers compare incidents and phenomena across subject for similarities and differences in properties, dimensions, and processes (Corbin and Strauss 1990).

The developers of this method note that "data are grouped and conceptually labeled. Then concepts are categorized. Categories are linked and organized by relationship, conditions and dimensions" (Scott 2004). In the first phase (open) of coding, conceptual labels were given to preliminary groupings of like phenomena (Corbin and Strauss 1990). In the second phase, axial coding, the researchers returned to the data to revise hypotheses and strengthen conceptual links. In the later stages of coding, often termed selective, categories were again refined and "unified around...core...categor[ies that] represent[ed] the central [findings] of the study" (Corbin and Strauss 1990, p. 14). 
Initially, a team of two researchers (the first author and an outside researcher) analyzed the transcripts question by question and identified a total of 118 codes such as "growth in the area of working in a multidisciplinary team," "getting medical knowledge," "value life more," "not taking health for granted," and "getting in touch with your own grief." These codes were refined through the constant comparison method to form 34 categories. The 34 categories identified were then grouped into two major themes: 28 categories (e.g., "emotional exhaustion," "allowing myself to experience grief," "being part of people's lives," "professional growth") formed the major category "impact of caring for dying children on professionals' personal and professional lives." The remaining six categories (e.g., "enjoying nature," "listening to music," "interaction with loved ones") were combined to form the second major category, "self-care methods." The two major themes were identified through the process of axial coding by comparing and contrasting the categories across the study.

For example, from the 34 categories identified initially, 18 different categories (e.g., "value life more," "sort-out what is really important," "more understanding") were grouped under the label of impact of working with dying children on professionals' personal lives. These initial codes were grouped and named, whenever possible, based upon the language used by the participants themselves. At this stage of coding, stringent efforts were made to honor and highlight the participants' language (Constas 1992). The researchers then combined them in three more dense categories: shifts in priorities (e.g., "value life more," "value my own children," "more tolerant"), shifts in relationships (e.g., "more caring, intimate," "more distanced," "shift in relationship with self around grief," "importance of clarity in relationships"), and no impact. The names of the final labels were based on the findings from the literature (Becvar 2003; Kaplan 2000; Papadatou 2000), this method being known as theoretical sampling of the data (Corbin and Strauss 1990).

This process was repeated until no new redundancies or exceptions, often labeled theoretical saturation, were located that could add to the richness of the description (Corbin and Strauss 1990). Utilizing this process and criteria as a guide, the lead researcher then completed the analysis.

\section{Quality Control}

A number of measures were taken during the study to insure trustworthiness. First, all of the interviews were conducted by one of the researchers, enabling the collection of three different types of data: transcripts, personal observations, field notes. Second, all of the transcripts were analyzed independently by two researchers. The same researchers analyzed together the process of coding and the categories. Third, the second author, who did not participate in the analysis of the data, reviewed the process of coding, thus safeguarding what in the qualitative research literature is referred as external reliability: "the likelihood that an independent researcher would find similar phenomena or generate the same constructs in the same or similar settings" (Echevarria-Doan and Tubbs 2005, p. 57).

\section{Findings}

For the sake of clarity, the final findings of the study are presented in two main groupings. The first area comprises the impact of caring for dying children on professionals' personal and professional lives. Although our initial intent (see questions 5 and 7 in Apendix A) was 
to make a distinction between the costs and the rewards experienced by interviewees, the comments from participants taught us that the costs and the rewards are intertwined. Therefore, we decided to present these findings in a broad category labeled impact rather than separate categories for costs and rewards. The second grouping of data relates to helpful self-care methods used by the participants. Quotes from the interviews are presented within each main grouping, both to honor the participants' experiences and to illustrate themes.

The Impact of Caring for Dying Children on Professionals' Personal and Professional Life

\section{The Greatest Gift}

Without exception, all the participants in the study mentioned as the most important reward the chance to be part of people's lives in a particularly difficult situation. Two quotes illustrate this sentiment:

I always thought that this is a privilege: to meet these families, to have them let me share with them this special time in their lives, to let me try and help them find the best way to deal with it. (Female MFT 1)

The biggest gift a family can give you is to let you in their life when they are in the midst of things like that. It is a gift to see the grace they show. It was astonishing to me. That was the biggest present to me: families allowing me to be there in probably the worst times of their lives. (Female Nurse)

\section{Shifts in Priorities, Relationships, and Beliefs about Life and Death}

All the participants acknowledged that working in these particular settings encouraged some shifts in how they create meaning and their views on the purpose of life. Regardless of the length of time they have been caring for dying children, every participant mentioned a shift in the way they think about priorities in life, and/or relationships, and/or death.

Shifts in priorities. Most of the participants described how their work setting impacted what they think about priorities in their lives. For example,

It emphasized how important it is to be as clear as you can with people in your life because you never know if they are going to be diagnosed with something and are going to die in three months. I noticed for myself, when there is clarity in the relationship I can do the grief work better. (Female MFT 4)

It helped me appreciate what is really important: when my kids were small I used to worry about them digging in the dirt, and licking their fingers. But now I think every child should dig in the dirt and lick their fingers. It helped me sort out for myself what I believe is important and what things I can really let go of. (Female Nurse)

Most of the participants recognized that after their experience with dying children, life in general became more valuable for them. As one of the interviewees expressed it: "I learned to enjoy small things. So I am very happy when I get up and the sun is shining." (Female MFT 2)

Shifts in relationships. Participants also observed a shift in their relationships with their loved ones. They described experiences in their relationships as being more nurturing, more intimate. Some of them noticed that they felt the need to become closer to others: 
I need to talk when I feel overwhelmed. I need to open the faucet and let the water out. I need to cry not only for them but for the piece of loss I experience with them. I try to do better with crying and sharing with others. (Female MFT 2)

Other participants described experiences with their family members or close friends as being more caring with them, more empathetic toward their difficult work roles. For example, "Some friends have just been amazing; they are really interested in, checking in with me, how I feel, if I take care of myself. They are wonderful."(Female MFT 3)

On the other hand, other participants noticed a distance in some of their close relationships that they attributed to the perception of others regarding their work in settings where children die:

I have some friends that are not able to talk about their feelings related to me working here, and about children that are dying or at risk of dying so that they stay away of it. I have to be careful about what I am talking, like talk about my day, with certain people. I cannot talk about it. (Female MFT 3)

I tend more towards having strict boundaries. On that continuum I am not at the enmeshment end, I am more in the distancing end and I think that protected me professionally and of course that also means that I have more distant relationships. (Female MFT 4)

One participant noticed a shift in relationship with self around loss and grief, particularly feeling that it was triggered by her professional role.

It helped me get in touch with my own grief, sadness and pain. Being a therapist and before having this position, the process of holding other people's pain sort of allowed me to not hold my own. Now, I guess I have been in this journey of reclaiming the tears for myself. (Female MFT 2)

Shifts in beliefs about death. Most participants expressed the fact that caring for dying children made them aware of the fact that children do die, that death does not occur only at the end of a long life. One interviewee said: "I did painfully learn that children do die all the time." (Male Social Worker)

Another interviewee referred to a personal awareness that her child could die, as a result of her work exposure to families that experienced death of a child:

Sometimes I am worried and I ask myself: Did God lead me into this so to have an understanding when it is going to happen to me? This is a piece that is obviously lingering in my mind and now working here I know it is a possibility. (Female MFT 2)

One of the MFTs interviewed noticed that her work role made her question what death really is and how death does or does not change the relationship with the deceased:

While the child is still alive but you know that she is going to die, already your internal experiences with her changes and afterwards, there is still an internal experience of her similar to what it was when she was alive. So that makes me ask what death really is, what is connected to the body and what is not. (Female MFT 3)

A frequent comment of the participants relates to this type of shift in how they normalize suffering and death:

I have learned that the denial of the presence of suffering and our impermanence, and seeing these things as problematic in the sense that we should control them, the 
resistance to these things causes the problems people are coming to therapy. (Female MFT 3)

Another participant mentioned the shift she experienced around her beliefs about death as a reward of working with dying children: "My role has helped me to see that death is not always the worst thing to happen. Death can be a blessing versus living with a bad injury or illness." (Female Nurse)

\section{Professional Growth}

All the participants agreed that working with dying children helped them gain more medical knowledge in general, and specifically more knowledge about children's lifethreatening diseases or injuries. Also, all agreed this knowledge was important in assisting children and families with end-of-life issues.

A couple of topics were mentioned exclusively by the MFTs interviewed for this study. While all seven participants mentioned growth in the area of working in a multidisciplinary team, only the MFT participants mentioned an enhancement of their therapeutic skills as well.

At my previous job I had to work in a multidisciplinary team as well but it was not such an integration of care as it is here. Here I feel more exposed with what I do. Soon after coming here I realized that here people are used to work in teams and that even though I am going to have my private time with patients in therapy a lot of my job is on the open. That was a big change for me. (Female MFT 3)

The same therapist noticed that part of her job in this multidisciplinary teams, as a systems specialist, was to address the issues from a larger perspective:

I think a family therapist is a systemic therapist and when a family comes to the hospital becomes part of a larger system, which includes the pre-existent system, meaning the medical system, all the staff. Even though it is not highlighted in my job description, it is pretty clear for me that it is an important part of my job to be there for the staff as much as for the families, because for the families the primary providers are the medical professionals; so I am there to help them do their job. (Female MFT 3)

Another MFT who previously had worked with dying children in a multidisciplinary team expressed her regret about not having the multiple perspectives of such team work now as a private practitioner:

For me working in a multidisciplinary team is invigorating and challenging because as a MFT you have many perspectives on how to work with a family. I loved that, I really enjoyed being in a team and I miss it now. (Female MFT 4)

\section{Costs}

When asked about the costs of caring for dying children, every one of the participants mentioned emotional exhaustion. They described how this type of exhaustion impacted both their professional and personal lives. To describe this phenomenon they used words such as: "overwhelming," "draining," "frustrating," "job becomes a burden," "devastating sadness," "not a lot to give to others emotionally at the end of the day." These words 
were used to describe events that involved the actual death of a child as well as to represent the costs of this particular type of work.

One of the MFTs interviewed described her experience with the death of a particular child whose family she consistently worked with as being "devastating:" "I could not stop crying for 2-3 days after the child's death. I myself I was astonished by how much impacted me." (Female MFT 4)

Another female MFT explained that the emotional exhaustion translates into feeling physically drained as well, which creates a pressure on fulfilling one's responsibilities both at work and at home: "What I think is the biggest cost for me working here is that it does take a lot out of me emotionally and then that emotional exhaustion kind of leads into being physically drained." (Female MFT 1)

Another price to be paid while caring for dying children is the potential of not having enough emotional resources left to invest in intimate relationships. This cost was identified by 4 of the interviewees. For example:

When I get home I do not necessarily have a lot left for anyone else. I just stare at the walls for a couple of hours and then go to bed. In doing that I am able to get up again the next morning and do it again the next day. It is an emotional drain in that when I leave here I do not have a lot left to give to anyone else. (Female Nurse)

For half of the participants, another cost that comes with caring for dying children is a hypervigilance about death: "My perspective about death has shifted so much and in some ways I became very aware that death can happen all the time and no one can get away of this awareness entirely." (Female MFT 2)

Another participant in the study explained how difficult it is for her to categorize the hypervigilance about death as being a cost:

I guess it is a cost, but I could not perceive it as a cost until I am sitting here answering your questions, this heightened awareness that death can come out of nowhere; it can be very quick and very painful and none of us can be exempt from that. (Female Nurse)

\section{Self-care Methods}

The second over-arching category was related to self-care methods. The 21 initial codes were grouped into 5 categories: "Close/intimate interactions with others," "self-work" (reading, writing, meditation, praying), "maintaining good physical health," "enjoying nature," and "listening to music." These categories were synthesized further into two main themes: close/intimate interaction with others (family/friends, co-workers) and individual self-care methods. In the second theme the interviewees mentioned reading, writing, meditation, allowing oneself to experience intense feelings related to work experiences, maintaining a good physical health, enjoying nature, and listening to music.

\section{Close Intimate Interaction with Others}

Six of the interviewees recognized the importance of their intimate relationships when talking about self-care methods: 
Probably I do not get to see my grandchildren as I would like to, but seeing them is a good fix. I also have a new relationship with a male friend that is very important to me. (Female Chaplain)

By just trying to do something with my family during the weekends. (Female MFT 1)

I noticed that ever since I started this job I enjoy more being home with my family. (Female MFT 3)

In addition, four of seven participants highlighted the importance of having strong relationships with their co-workers and the opportunity to process their experiences with them. In this regard "peer-supervision" was the word most used to describe the help professionals receive from their co-workers.

One of the participants mentioned that she has a group of friends, current or past coworkers, who are a very important support for her and with whom she meets periodically outside the work setting:

I know that at the end of the day I can call either one of them and speak what is on my mind, and have a really good conversation. I know that because they walked on that path before they know what I am saying, and where I am coming from, and this is very helpful to me. (Female Nurse)

\section{Individual Self-Care Methods}

The majority of the participants (six out of seven) mentioned the use of reading, writing, and meditation as methods of self-care through internal work.

Journaling is something that I do now more than ever before and it is extremely helpful. I write about the events and also how I distract myself for at one point I distract myself from the experience. Another thing I tend to do is to write poetry because it is very concise. Journaling is much more of a rambling thing. They both are helpful to me. (Female MFT 3)

When I have a chance I try to do meditation while at work, just try to relax and not to think about too many things at once. So if I have a chance I would find a spot and try to do it even for just ten minutes. (Male Social Worker)

Maintaining good physical health through eating healthy and physical activities was another theme found as an answer to question 6 (see Appendix A). Four of the participants highlighted the importance of keeping in good health as a self-care method:

There are some things that I am careful with, like make sure that I eat the right food and exercise even though this is a challenge for me lately since I am very busy. (Female MFT 3)

I try to go to the gym, and at work I avoid elevators, try to take walks and I am pretty careful with what I eat. I noticed that when I do these I feel more energized at work. (Female Chaplain)

\section{Discussion}

The purpose of this qualitative study was to learn from the professionals' lived experiences about the impact of working in settings where children with life-threatening diseases are 
treated. Specifically, we were interested in the meaning professionals ascribe to their role, with a particular interest in the voices of MFTs. The other professionals involved in the study are or have been team members of some of the MFTs involved in the study.

It is known from the literature that working with death and dying issues in general (Becvar 2003; Henning 2005; Lyckholm 2001; Pensson et al. 2000; Witt Sherman 2004) and with dying children in particular (Davies et al. 1996; Kaplan 2000; Lattonzi-Licht in Papadatou and Papadatou 1991; Papadatou 2000; Papadatou et al. 2002; Rashotte et al. 1997; Rushton 2004) can be a risk factor for professional burnout. Listening to the interviewees' voices, we have learned that MFTs share some commonalities with their team members and also have some unique issues with which to deal.

As with their team colleagues from other professions, MFTs report that the greatest gift of their day to day work with families with a dying child is the opportunity to be part of their lives and to be exposed to the resilience of the families in these exceptionally painful circumstances. It seems that for those who persevere in this work position, the gift of accompanying families with very ill children somehow outweighs the emotional exhaustion caused by their work. Furthermore, witnessing families' resilience and cohesion (Weingarten 2003) seamed to strengthen the professionals' own resilience and to inspire them with a sense of awe for the humanness and beauty that is brought to the surface in the midst of extreme circumstances. This work also seems to create a sense of pride in a common humanity with the resources to fight life's challenges. This finding is supported by the literature reviewed, including Becvar (2003), who states:

for professionals who choose to care for those that are dying and/or grieving, the opportunity and privilege of working in the presence of grief is often considered a great gift. The general attitude is one of gratitude of being able to help and support individuals and family members around end of life issues with all their complexities.

Part of the gift the MFTs and their team partners talked about is the opportunity to create meaningful healing relationships wit those with whom they work. Family members as well as therapists are challenged by the difficult circumstances they face. Such difficulty invites vulnerability and fosters truly intimate and meaningful relationships that are themselves a powerful tool for healing.

Relative to meaning-making, in their article on vicarious traumatization, McCann and Pearlman (1990) refer to several "psychological needs" or "schemas" that can be disrupted by trauma: safety, dependency/trust, power, esteem, intimacy, independence, and frame of reference. The authors assert that "working with trauma survivors can also disrupt the therapists' schemas in these areas" (p. 137). In our study, we found that an important shift mentioned by all MFTs interviewed was in their "frame of reference" and their meaning-making about death. Participants repeatedly noted that their work experiences heightened awareness about the fact that children die, that suffering is a normal part of life, that human beings are impermanent, and also that death is not so devastating but rather a normal part of life. MFTs, like other professionals working with dying children, cannot escape this existential dilemma: "What is death?" At first, participants seem to ask this question in a general, rhetorical way. Then the question becomes more specific "What does the death of this particular child mean?" In the end, participants seemed to face their own mortality with questions such as "What is my death going to be like?" or "Is there something else after death?" These existential questions can challenge all helping professionals because they trigger tender feelings and experiences from the professionals' own lives, feelings that often are avoided. However, clinicians focusing on death and dying 
issues do not have this choice because of the realities with which they are faced every day. Standing at the foot of a bed of a child near death pushes one to question the meaning and purpose of suffering, death, and life after death.

In the literature on other health professionals working with dying children, Davies et al. (1996), Papadatou (2000), and Papadatou et al. (2002) mention the death meaning-making process as being part of healthy grief work. Referring to how caregivers make meaning about the death of children they work with, Papadatou (2000) states that "any form of meaning provides health professionals with a sense of mastery, and help[s] them overcome any state of confusion, of doubt, or of meaninglessness" (p. 67). Our study goes a step further by trying to see how professionals' "schemas" (McCann and Pearlman 1990) around death shifted as a result of caring for dying children.

MFTs and their co-workers in this study reported paying a price when caring for dying children. One part of this cost can lead to isolation and withdrawal. The participants highlighted the importance of being in nurturing relationships while working with dying children. A lack of emotional engagement is a real risk factor in intimate relationships and can prevent professionals from having this important self-care method (Becvar 2003; Papadatou 2000; Rushton 2004). Indeed, being emotionally available in the therapy room is one of the most important ingredients for a strong therapeutic relationship as well (Satir et al. 1991), and a good client-therapist relationship contributes a great deal to a successful outcome of therapy (Bachelor and Horvath 1999; Lambert 1992). Thus, a therapist who is not available emotionally can impair the results of therapy. In her qualitative study of 15 pediatric nurses who treated dying children, Kaplan (2000) found that all participants "acknowledged that fully expressing their feelings was a critical element for maintenance of mental and physical health and professional continuity" (p. 194).

MFTs did describe several experiences that differed from their colleagues from other fields. Perhaps because of their systemic training, MFTs seemed to take into consideration the pain of the larger system involved with the families and their ill children (e.g., when other professionals in the team reach out to MFTs wanting to talk about the death of a child that they cared for). As systemic thinkers and practitioners, they seemed to feel a responsibility to support their team members in dealing with death and dying issues every day. This finding is consistent with findings in the literature reviewed, more specifically the literature on medical family therapy. McDaniel, Hepworth and Doherty (1992) suggest:

Medical family therapists can support grieving medical team members. Although the medical family therapist is part of the treatment team, the therapist can be the catalyst for encouraging team members to discuss their responses to a particular family and loss (p. 249).

Participants did recognize that offering this type of support helps them through the relationships they develop with their co-workers. As an example, peer-supervision was one of the self-care methods considered the most useful by all the MFTs participating in the study. They also felt a responsibility to facilitate relationships between team members. One of the MFT participants in our study said:

It felt to me at times that I am orchestrating all the professionals, helping to make the relationships work more than to be a family therapist for that particular family but through that really helping the family. (Female MFT 4) 


\section{Clinical and Training Implications}

The findings of this study suggest implications for MFTs who practice in settings where children with life-threatening diseases are treated. MFTs, like other professionals caring for dying children, should be aware of the emotional impact such work can have on their personal well-being. Also, MFTs must recognize that in addition to the impact that emotional exhaustion can have on their work performance, it also can impact relationships outside of work. Thus, it is crucial that MFTs develop self-care practices, preferably from the beginning of their work in these settings (Rosenberg and Pace 2006).

As Becvar (2003) notes in this regard, MFTs entering the field of work with dying children and their families should have the "opportunity to explore their motivations" (p. 476) as well as to address issues in their personal lives, especially issues related to loss, that might impede their effectiveness in the therapy room.

One particular finding, so powerfully described by participants in this study, is the 'nothing left in the tank' phenomenon at the end of a day working with dying children. Feedback from participants suggests that clinicians would do well to develop routines or rituals that help to transition from work to home each day. As the findings suggest, some clinicians wish to leave work at work while others feel a deep need to connect with family or friends around issues of loss in their workday. Regardless of the personal coping style, the findings from this study point to the need for daily practices that help with the transition from work to home if the clinician desires to stay present in both places.

MFTs also should be aware when choosing to work in a medical setting that part of their responsibility is to the larger system, and that their team partners from other professions (nurses, physicians, social workers, chaplains, child life specialists) may turn to them for comfort and support. This can add to the emotional pressure and increases the risk of burnout. Thus, part of the MFTs' training to prepare to enter any medical field should address working collaboratively in a multidisciplinary team and the MFTs' potentially unique role on the team (Gawinski et al. 1999; McDaniel et al. 1992; Muchnik et al. 1993; Seaburn et al. 1996).

\section{Limitations of the Study and Future Research Directions}

This study has several weaknesses. First and foremost, the small sample size limited the breadth of responses. Second, the semi-structured questionnaire has the potential to limit the depth of the responses. A number of additional, important questions were raised in the current study that could be included in future research. For example, how do the work experiences of MFTs who have children of their own differ from those of the MFTs who do not? How does the age of the ill child influence MFTs' experiences? Perhaps most importantly, how does previous personal experience with death impact MFTs' ability to make meaning out of their work experiences? And finally, what is it that allow some MFTs to work longer than others in these settings?

In conclusion, as the medical field continues to shift toward an increased acceptance of systemic, collaborative, and family-based treatment models, the opportunities for medical family therapy training and practice also increase. As a result, more MFTs will be facing the unique strains and receiving the special rewards that such work entails. The contribution of the current study is that it serves as a stepping-stone for future research that accesses and describes the real life experiences of MFTs working with loss and death issues in a medical setting. The findings describe MFTs attempts to successfully manage 
working in a highly intense work setting with a life outside of work, a balance though difficult to achieve still seems possible.

Acknowledgement Special thanks to Brittany Edge who helped through out the process of analyzing the transcripts of the interviews.

\section{Appendix A}

\section{Questionnaire}

1. How did you decide to work here?

2. How has working here made an impact on your professional life?

3. How has working here made an impact on your personal life?

4. Have your beliefs around death changed since working here? If yes, how?

5. What are the costs of working here?

6. How do you take care of yourself?

7. What are the rewards of working here?

Tell me about an event that impacted you the most working here.

\section{References}

American Psychiatric Association. (2000). Diagnostic and statistical manual of mental health disorders (4th ed., Text revision). Washington DC.

Bachelor, A., \& Horvath, A. (1999). The therapeutic relationship. In M. A. Hubble, B. L. Duncan, \& S. D. Miller (Eds). The heart and soul of change: What works in therapy (pp. 133-178). American Psychological Association.

Becvar, D. S. (2003). The impact on the family therapist of a focus on death, dying, and bereavement. Journal of Marital and Family Therapy, 29(4), 469-477.

Blaga, L. (1982). Poezii. Bucuresti: Editura Cartea Romaneasca.

Canfield, J. (2005). Secondary traumatization, burnout, and vicarious traumatization: A review of the literature as it relates to therapists who treat trauma. Smith College Studies in Social Work, 75(2), 81101.

Catalan, J., Burgess, A., Pergami, A., Hulme, N., Gazzard, B., \& Phillips, R. (1996). The psychological impact on staff of caring for people with serious diseases: The case of HIV infection and oncology. Journal of Psychosomatic Research, 40(4), 425-435.

Constas, M. A. (1992). Qualitative analysis as a public event: The development of category development procedures. American Educational Research Journal, 29, 253-266.

Corbin, J., \& Strauss, A. (1990). Grounded theory research: Procedures, cannons, and evaluative criteria. Qualitative Sociology, 13, 3-21.

Davies, B., Cook, K., O’Loanne, M., Clarke, D., MacKEnzie, B., Stutzer, C., Connaughty, S., \& McCormick, J. (1996). Caring for dying children: Nurses' experiences. Pediatric Nursing, 22(6), 500-507.

Dunkley, J., \& Whelan, T. S. (2006). Vicarious traumatisation: Current status and future directions. British Journal of Guidance and Counselling, 34(1), 107-116.

Dye, J. F., Schatz, I. M., Rosenberg, B. A., \& Coleman, S. T. (2000). Constant comparison method: A kaleidoscope of data. The Qualitative Report, 49(1/2). Retrieved April 19, 2005, from http://www.nova.edu/ssss/QR/QR3-4dye.html.

Echevaria-Doan, S., \& Tubbs, C. Y. (2005). Lets get grounded: Family therapy research and grounded theory. In D. H. Sprenkle \& F. P. Piercy (Eds.), Research methods in family therapy (2nd ed., pp. 4162). New York: The Guilford Press.

Figley, C. R. (Ed.), (1995). Compassion fatigue: Coping with secondary traumatic stress disorder in those who treat the traumatized. New York: Brunner-Routledge.

Frankl, V. (1984). Man's search for meaning: An Introduction to Logotherapy. New York: Touchstone. 
Friedman, R. (1985). Making family therapy easier for the therapist: Burnout prevention. Family Process, 24, 549-553.

Gawinski, B. A., Edwards, T. M., \& Speice, J. (1999). A family therapy internship in a multidisciplinary healthcare setting: Trainees' and supervisor's reflections. Journal of Marital and Family Therapy, 25(4), 469-484.

Henning, J. A. (2005). Becoming a therapist with ill, dying, and bereaved: A relational constructivist view. Dissertation submitted to the Faculty of The Chicago School of Professional Psychology.

Hesse, A. R. (2002). Secondary trauma: How working with trauma survivors affects therapists. Clinical Social Work Journal, 30(3), 293-309.

Kaplan, L. J. (2000). Toward a model of caregiver grief: Nurses experiences of treating dying children. Omega: Journal of death and dying, 41(3), 187-206.

Kazak, A. E., Alderfer, M., Rourke, M. T., Simms, S., Streissand, R., \& Grossman, J. R. (2004). Posttraumatic stress disorder (PTSD) and Posttraumatic stress symptoms (PTSS) in families of adolescent childhood cancer survivors. Journal of Pediatric Psychology, 29(3), 211-219.

Lambert, M. J. (1992). Implications of outcome research for psychotherapy integration. In J. C. Norcross \& M. R. Goldfried (Eds.), Handbook of psychotherapy integration (pp. 94-129). New York: Basic Books.

Lattonzi-Licht, M. (1991). Professional stress: Creating a context for caring. In D. Papadatou \& C. Papadatos (Eds.), Children and death (pp. 203-311). New York: Taylor and Francis.

Lyckholm, L. (2001). Dealing with stress, burnout, and grief in the practice of oncology. The Lancet, Oncology, 2, 750-755.

McCann, I. L., \& Pearlman, L. A. (1990). Vicarious traumatization: A framework for understanding the psychological effects of working with victims. Journal of Traumatic Stress, 3, 131-149.

McDaniel, S. H., Hepworth, J., \& Doherty, W. J. (1992). Medical Family Therapy: A biopsychosocial approach to families with health problems. Basic Books: New Edition ed.

McLean, S., Wade, T. D., \& Encel, J. S. (2003). The contribution of therapist beliefs to psychological distress in therapists: An investigation of vicarious traumatization, burnout and symptoms of avoidance and intrusion. Behavioral and Cognitive Psychotherapy, 31, 417-428.

Muchnik, S., Davies, B., Getzinger, A., Rosenberg, A., \& Weiss, M. (1993). Collaboration between family therapy and healthcare: An internship experience. Family Systems Medicine, 11, 271-279.

Papadatou, D. (2000). A proposed model of health professionals' grieving process. Omega: Journal of Death and Dying, 41(1), 59-77.

Papadatou, D., \& Papadatou, C. (Eds.). (1991). Children and death. New York: Taylor and Francis.

Papadatou, D., Papazoglou, I., Bellali, T., \& Petraki, D. (2002). Greek nurse and physician grief as a result of caring for dying children. Pediatric Nursing, 28(4), 345-353.

Pearlman, L. A., \& Saakvitne, K. W. (1995). Treating therapists with vicarious traumatization and secondary traumatic stress disorders. In C. R. Figley (Ed.), Compassion fatigue: Coping with secondary traumatic stress disorder in those who treat the traumatized (pp. 150-177). NY: Brunner/Mazel.

Pensson, R. T., Dignan F. L., Canellos, G. P., Picard, C. L., \& Lynch, T. L. (2000). Burnout: Caring for the caregivers. The Oncologist, 5, 425-434.

Rashotte, J., Fothergill-Bourbonnais, F., \& Chamberlain, M. (1997). Pediatric intensive care nurses and their grief experiences: A phenomenological study. Heart \& Lung, 26, 372-386.

Ricoeur, J., \& Gentet, J. C. I. (1996). Fratrie et cancer. A propos de quelques observations. Neuropsychiatrie de l'enfance et de l'adolescence, June-July, 258-267.

Rosenberg, T., \& Pace, M. (2006). Burnout among mental health professionals: Special considerations for the Marriage and Family Therapist. Journal of Marital and Family Therapy, 32(1), 87-99.

Rushton, C. H. (2004). The other side of caring: Caregiver Suffering. In B. S. Carter \& M. Levetown (Eds.), Palliative care for infants, children and adolescents (pp 220-243). The Johns Hopkins University Press.

Satir, V., Banmen, J., Gerber, J., \& Gomori, M. (1991). The Satir model: Family therapy and beyond. Palo Alto, CA: Science and Behavior Books.

Seaburn, D. B., Lorenz, A. D., Gunn, W. B. Jr., Gawinski, B. A., \& Mauksch, L. B. (1996). Models of collaboration: A guide for mental health professionals working with health care practitioners. Basic Books.

Scott, K. W. (2004). Relating categories in grounded theory analysis: Using conditional relationship guide and reflective coding matrix. The Qualitative Report, 9(1), 113-126. Retrieved April 19, 2005 from.

Weingarten, K. (2003). Common shock: Witnessing violence everyday. New York: Dutton Books.

Witt Sherman, D. (2004). Nurses' stress \& burnout: How to care for yourself when caring for patients and their families experiencing life-threatening illness. American Journal of Nursing, 104(5), 48-56. 